\title{
Bronchial Anthracosis - Anthracofibrosis: Potential Causes and Clinical Characteristics
}

\author{
Elif Yılmazel Uçar, Ömer Araz, Metin Akgün, Mehmet Meral, Leyla Sağlam, \\ Hasan Kaynar, Ali Metin Görgüner
}

Department of Pulmonary Diseases, Atatürk University Faculty of Medicine, Erzurum

\begin{abstract}
Objective: Anthracosis is characterized by accumulation of black pigment in the bronchial mucosa. It may cause anthracofibrosis by leading to mucosal destruction and deformity. In the present study, we aimed to investigate the underlying reasons and clinical characteristics of cases, in which anthracosis-anthracofibrosis was detected via bronchoscopy.

Methods: The study comprised of 109 patients, in whom anthracosis -anthracofibrosis was detected by bronchoscopy between 2002 and 2012. Underlying reasons and clinical characteristics of the patients were analysed by reviewing medical records. The study was designed as a retrospective cohort study.

Results: The present study included 52 males (47.7\%) and 57 females (52.3\%) with a mean age of 67.8 9.8 (34-85) years. Of the patients, 66 (60.6\%) had exposure to biomass smoke, 38 (34.9\%) had a history of smoking and 5 (4.5\%) had occupational exposure. In bronchoscopy, 34 patients were shown to have anthracosis and 75 patients had anthracofibrosis. The right upper lobe (76 patients, 69.7\%) and the left upper lobe (74 patients, 67.9\%) were the most commonly involved sites; cough (58.7\%) and dyspnoea (49.5\%) were the most common symptoms, followed by chest pain (36.7\%). The most common radiological findings were atelectasis $(65.1 \%)$ and consolidation (55\%). Of the patients, $46.8 \%$ had chronic obstructive pulmonary disease (COPD), $24.8 \%$ had pneumonia, $18.3 \%$ had tuberculosis and $10.1 \%$ had malignancy.
\end{abstract}

Conclusion: Biomass smoke exposure is the most important risk factor for patients with anthracosis-anthracofibrosis. Such patients should be evaluated and followed-up for various pulmonary diseases including COPD, pneumonia, tuberculosis and malignancy.

Keywords: Anthracosis, anthracofibrosis, bronchoscopy

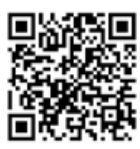

Received date: 08.05 .2013 Accepted date: 24.08.2013

Address for correspondence Elif Yllmazel Uçar, Department of Pulmonary Diseases, Atatürk University Faculty of Medicine, Erzurum, Turkey

E-mail: eucar1979@yahoo.com

(C) Copyright 2014 Turkish Respiratory Society (TRS) DOI: 10.5152/ejp.2014.72681

- Available online at www.eurasianjpulmonol.com

\section{INTRODUCTION}

The term bronchial anthracosis (BA) is defined as black pigmentation of the bronchial mucosa (1). Bronchial anthracofibrosis (BAF) is defined as anthracotic pigmentation accompanied by bronchial stenosis or obliteration (2).

Diagnosis of bronchial anthracosis and/or anthracofibrosis can be made by bronchoscopic evaluation. Although, in general, BA occurs due to the accumulation of carbon particles, also iron, lead, cadmium and other inorganic or organic materials may cause BA. It is usually detected in patients with obstructive pulmonary disease, who do not completely respond to treatment and had radiological abnormalities (3). It is more prevalent among advanced age females living in the rural areas. However, there is no clear clinical approach concerning the underlying reasons and clinical characteristics of patients, in whom anthracosis or BAF is detected.

In the present study, we aimed to investigate the underlying reasons and clinical characteristics of patients, in whom anthracosis-anthracofibrosis was detected via bronchoscopy. 
Table 1. Epidemiological and clinical characteristics of the patients

\begin{tabular}{|l|c|}
\hline Characteristics & Values \\
\hline Age (years) (mean \pm SD) & $67.8 \pm 9.8(34-85)$ \\
\hline Male/Female $n(\%)$ & $52 / 57(47.7 / 52.3)$ \\
\hline Risk Factors $n(\%)$ & \\
Smoking & $38(35)$ \\
\hline Biomass & $66(61)$ \\
\hline Occupational & $5(4)$ \\
\hline Symptoms $n$ (\%) & \\
\hline Cough & $64(59)$ \\
\hline Dyspnoea & $54(50)$ \\
Chest pain & $40(37)$ \\
\hline Weight loss & $15(13.8)$ \\
\hline Fatigue-weakness & $16(15)$ \\
\hline Blood in sputum & $5(5)$ \\
\hline PFT (n=89) (mean $\pm S D)$ & \\
\hline FVC expected \% & \\
\hline FEV ${ }_{1}$ expected \% & $90.6 \pm 20.1$ \\
\hline FEV ${ }_{1} /$ FVC & $70.2 \pm 30.5$ \\
\hline n: Patient number; SD: standard deviation; PFT: pulmonary function test \\
\hline
\end{tabular}

\section{METHODS}

\section{Patient Population}

In the present study, the reports of 2536 patients, of whom bronchoscopy records were available between 2002 and 2012, were reviewed. Medical records of 109 out of 200 patients, in whom anthracosis or BAF had been detected, were available. Patients, whose medical records were unavailable, were not included in the study.

\section{Study Design}

The study was planned as a retrospective cohort study. Medical files of the patients, in whom BA and/or BAF was detected via bronchoscopy, were reviewed. Clinical and radiological characteristics of the patients were recorded. Consents of all patients were obtained prior to bronchoscopy. The study protocol was approved by the Local Ethics Committee.

\section{Interventions}

Patients that underwent bronchoscopy were included in the study. Prior to bronchoscopy, routinely, $0.07-0.67 \mathrm{mg} / \mathrm{kg}$ midazolam (Dormicum; Cenexi Sas Fontenay, France) was used for sedation and $2 \%$ lidocaine (Aritmal; Osel Pharm. Co., Istanbul, Turkey) was used for local anaesthesia ( 5 cc for gargling and 4 puffs of spray on the vocal cords).

\section{Methods for Measurement}

Pulmonary function tests of the patients that were performed prior to bronchoscopy were examined. According to the American Thoracic Society (ATS) criteria, patients whose post-bronchodilator forced expiratory volume in one second $\left(\mathrm{FEV}_{1}\right) /$ forced vital capacity (FVC) ratio $<70$ were considered to have chronic obstructive pulmonary disease (COPD) (4). Postero-anterior chest $\mathrm{x}$-ray and tho-
Table 2. Bronchoscopic findings

\begin{tabular}{|l|c|c|}
\hline Localization & $\begin{array}{c}\text { Bronchial } \\
\text { Anthracosis } \\
(\mathbf{n}=\mathbf{3 4})\end{array}$ & $\begin{array}{c}\text { Bronchial } \\
\text { Anthracofibrosis } \\
(\mathbf{n}=\mathbf{7 5})\end{array}$ \\
\hline Right upper lobe & 10 & 15 \\
Left upper lobe & 10 & 10 \\
Right middle-lower lobe & 10 & 50 \\
Left lower lobe & 5 & 10 \\
\hline Right main bronchus & 4 & - \\
Left main bronchus & 2 & - \\
\hline n: Patient number & & \\
\hline
\end{tabular}

racic computed tomography of the patients were examined and radiological features were recorded.

\section{Statistical Analysis}

Statistical analysis was done using SPSS Windows version 17.0 (SPSS Inc. Chicago, IL., USA). Mean and standard deviation of data were calculated and descriptive analysis was done.

\section{RESULTS}

Of the 109 patients included in the study, 52 (47.7\%) were male and $57(52.3 \%)$ were female. The mean age of the patients was $67.8 \pm 9.8$ (34-85) years. While 38 (35\%) of the patients were smokers, $66(61 \%)$ had exposure to biomass smoke, and 5 (4\%), of which, 3 were coal miners and 2 were jean sandblasting workers, had occupational lung disease. These patients were diagnosed with pneumoconiosis and silicosis, respectively. All females with biomass smoke exposure were homemakers and all males with biomass smoke exposure were farmers, with a mean exposure period of $30 \pm 7$ years. The most common presenting symptoms of the patients were cough $(58.7 \%)$ and dyspnoea (49.5\%) followed by chest pain (36.7\%) and weight loss (13.8\%). Pulmonary function tests revealed a post-bronchodilator $\mathrm{FEV}_{1} / \mathrm{FVC}$ ratio $<70$ in 50 patients. General characteristics of the patients are presented in Table 1.

The most common radiological signs on PA chest $\mathrm{x}$-ray and computed tomography of the thorax were atelectasis $(n=71)$, consolidation $(n=60)$, mass $(n=18)$ and calcified or non-calcified hilar lymphadenopathy $(n=13)$. BAF was present in 51 of the patients with atelectasis $(p=0,003)$, and COPD and pneumonia were the comorbidities in these patients.

Bronchoscopy revealed pigmented lesions and/or bronchial stenosis in many areas (Figure 1,2). Thirty four patients had BA and 75 patients had BA and BAF. Particularly the right upper lobe $(n=76)$ and the left upper lobe $(n=74)$ were the most commonly involved sites. Bronchial anthracofibrosis was most frequently detected in the middle lobe $(n=50)$ (Table 2).

The most common comorbidities were COPD $(n=50)$ and pneumonia $(n=38)$. Tuberculosis was identified in 20 patients, of whom 10 had pulmonary tuberculosis and 2 had endobronchial tuberculosis. Eleven patients had lung cancer; with regard to the subtypes, 6 had squamous cell cancer and 5 had adenocancer. While BA was found together with BAF in 7 of these patients, BA or BAF was detected in separate segments in 4 patients. 


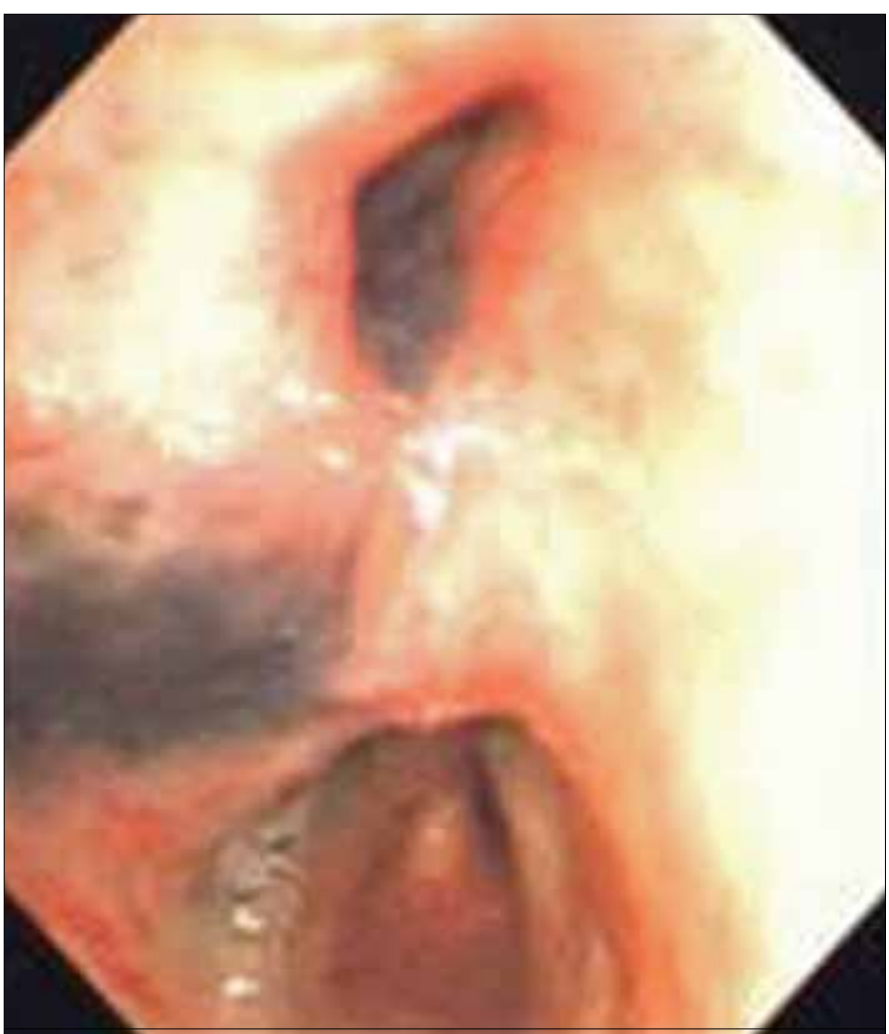

Figure 1. Bronchial anthracosis in the main carina and left main bronchus.

\section{DISCUSSION}

The present study revealed that biomass smoke exposure is the most important risk factor in BAF patients. COPD was the most common co-morbidity followed by pneumonia, tuberculosis and malignancy in patients with bronchial anthracofibrosis.

Biomass is being used as an energy source in $90 \%$ of rural areas in the developing countries (5). Homemakers in particular are exposed to biomass smoke during cooking and warming in poor environmental conditions (6). As the consequence of exposure, organic and inorganic particles of various diameters and carbon particles are accumulated in the bronchial mucosa (7). This accumulation may result in bronchial hypertrophy and stenosis. Studies $(3,8-13)$ demonstrated that biomass smoke exposure is a significant risk factor for the development of COPD particularly in rural areas. Likewise, in the present study, it was observed that biomass smoke exposure was the leading risk factor accompanied frequently by COPD, in patients with BAF.

In previous studies (8-14), the most frequent presenting symptoms of BAF patients were reported to be cough and dyspnoea. In the present study as well, $59 \%$ of the patients presented with cough and $50 \%$ presented with dyspnoea. In these patients, bronchoscopy was performed due to either unresponsiveness to conventional treatment or the presence of an accompanying radiological pathology. Atelectasis was the most common radiological pathology. This was deemed significant in terms of considering BAF in particularly female patients, who are at an advanced age, have biomass exposure and are unsuitable for bronchoscopy.

In addition to biomass smoke exposure, history of previous tuberculosis is also important in patients with bronchial anthracofibrosis. In

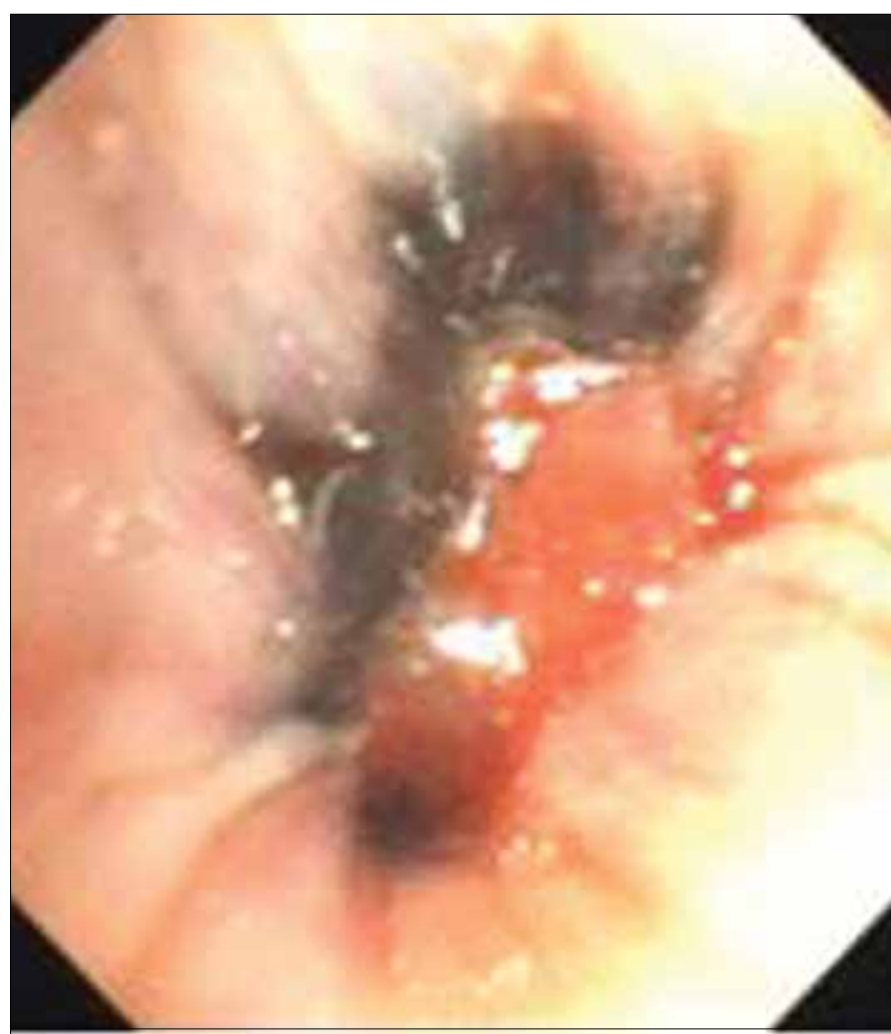

Figure 2. Bronchial anthracofibrosis in the entrance of the right middle lobe.

the present study, half of the BAF patients with tuberculosis were the patients with a history of tuberculosis in the past. Based on these results, no decision could be made whether BAF facilitates tuberculosis or tuberculosis facilitates BAF or both of them are comorbid conditions developing as a consequence of similar conditions. In addition to tuberculosis, pneumonia or malignancy may also accompany BAF. Of the patients, $35 \%$ had pneumonia and $10 \%$ had lung cancer.

\section{CONCLUSION}

Patients with bronchial anthracofibrosis must be evaluated in terms of risk factors, particularly for biomass smoke exposure. These patients should be evaluated and followed-up for various pulmonary diseases mainly for COPD, as well as for pneumonia, tuberculosis and malignancy.

Ethics Committee Approval: Ethics committee approval was received for this study from the ethics committee of Atatürk University.

Informed Consent: Written informed consent was obtained from patients who participated in this study.

Peer-review: Externally peer-reviewed.

Author contributions: Concept - E.Y.U.; Design - E.Y.U., Ö.A.; Supervision M.M., H.K.; Resource - H.K., A.M.G.; Materials - H.K., L.S.; Data Collection\&/or Processing - E.Y.U., L.S.; Analysis\&/or Interpretation - E.Y.U., M.A.; Literature Search - E.Y.U., Ö.A.; Writing - E.Y.U., Ö.A.; Critical Reviews - A.M.G., L.S.

Conflict of Interest: No conflict of interest was declared by the authors.

Financial Disclosure: The authors declared that this study has received no financial support.

\section{REFERENCES}

1. Naeye R L. The pneumoconiosis; coal worker's pneumoconiosis. In: Saldana M J, ed. Pathology of pulmonary disease. Philadelphia, PA, USA: J B Lippincott, 1994: 369-85. 
2. Chung MP, Lee KS, Han JG, Kim H, Rhee CH, Han YC, et al. Bronchial stenosis due to anthracofibrosis. Chest 1998; 113: 344-50. [CrossRef]

3. Kim YJ, Jung CY, Shin HW, Lee BK. Biomass smoke induced bronchial anthracofibrosis: presenting features and clinical course. Respir Med 2009; 103: 757-65. [CrossRef]

4. American Thoracic Society. Standardization of spirometry, 1994 update. Am J Respir Crit Care Med 1995; 152: 1107-36. [CrossRef]

5. Bruce N, Perez-Padilla R, Albalak R. Indoor air pollution in developing countries: a major environmental and public health challenge. Bull World Health Organ 2000; 78: 1078-92.

6. Gupta A, Shah A. Bronchial anthracofibrosis: an emerging pulmonary disease due to biomass fuel exposure. Int J Tuberc Lung Dis 2011; 15: 602-12. [CrossRef]

7. Churg A. The uptake of mineral particles by pulmonary epithelial cells. Am J Respir Crit Care Med 1996; 154: 1124-40. [CrossRef]

8. Özbay B, Uzun K, Arslan H, Zehir İ. Functional and radiological impairment in women highly exposed to indoor biomass fuels. Respirology 2001; 6: 255-8. [CrossRef]
9. Ekici A, Ekici M, Kurtipek E, Akin A, Arslan M, Kara T, et al. Obstructive airway diseases in women exposed to biomass smoke. Environmental Research 2005; 99: 93-8. [CrossRef]

10. Orozco-Levi M, Garcia-Aymerich J, Villar J, Ramirez-Sarmiento A, Anto JM, Gea J. Wood smoke exposure and risk of chronic obstructive pulmonary disease. Eur Respir J 2006; 27: 542-6. [CrossRef]

11. Moran-Mendoza O, Perez-Padilla JR, Salazar-Flores M, Vazquez-Alfaro F. Wood smoke-associated lung disease: a clinical, functional, radiological and pathological description. Int J Tuberc Lung Dis 2008; 12: 1092-8.

12. Sertogullarindan B, Gumrukcuoglu HA, Sezgi C, Akil MA. Frequency of pulmonary hypertension in patients with COPD due to biomass smoke and tobacco smoke. Int J Med Sci 2012; 9: 406-12. [CrossRef]

13. Kurmi OP, Devereux GS, Smith WCS, Semple S, Steiner MFC, Simkhada P, et al. Reduced lung function due to biomass smoke exposure in young adults in rural Nepal. Eur Respir J 2013; 41: 25-30. [CrossRef]

14. Törün T, Güngör G, Özmen I, Maden E, Bölükbaşı Y, Tahaoğlu K. Bronchial anthracostenosis in patients exposed to biomass smoke. Solunum 2007; 8: $48-51$ 